\title{
The Modification of PCFR Parameters \\ in Material Preparation Logic for EOL Stage
}

\author{
Wenxing Zhou, Yachao Wang \\ College of Management, Tianjin Polytechnic University \\ Tianjin 300160, China \\ E-mail: menkouz@yahoo.com.cn
}

\begin{abstract}
When enterprises begin to emphasize the department of customer service, the material preparation of safety stock becomes into the first problem for enterprises, and in various stages of safety stock preparation, the material preparation in the stage of EOL (End of Life) is the most important stage. In this article, we studied the PCFR of EOL stage in order to offer references for the material preparation in the stage of EOL for enterprise and increase the accuracy of material preparation in the stage of EOL for the department of customer service.
\end{abstract}

Keywords: Customer service, Safety stock, Last buy, PCFR

With the enhancement of customers' living level, their demands for products are not only limited in the function but more and more emphasized corresponding quality of after service customers would enjoy when quality problems occurs, i.e. after service or customer service what we usually called. Especially for the day when various product markets of supply and demand are gradually saturated, customer service more and more becomes into the concern focus for global famous brands, and enterprises begin to gradually transfer their views from the development of market to the establishment and perfection of customer service department. The satisfactory degree or customers' public praise will directly decide the market appropriation of the product brand market to some extent.

In numerous factors influencing customer service department, the safety stock water level of servicing material preparation is the very important one. The main influencing factor of safety stock water level rests with the period (Note 1) of material purchase, but in this article, we only study PCFR which is the key factor to influence the computation of Last Buy when the customer service department makes Last Buy in the stage of EOL.

As we know, for the center of customer service (Note2), the material preparation of safety stock can be divided into three stages according to the production cycle of product, i.e. the material preparation in the stage of NPI (New Product Introduce), the material preparation in the stage of MP (Multi-Produce), and the material preparation in the stage of EOL. For the stages of NPI and MP, the arrival of materials is only the problem of time, and the deficiency of materials is only temporary phenomena. But in the stage of product EOL, corresponding products will not be produced, but products are still in the stage of sale, i.e. even if the production is stopped at once, the products in sale still need warranted (Note3) period, so the customer service department still should prepare enough materials until the sales products pass the warranted period (Note4). Because the materials of EOL could not be obtained subsequently, so the accuracy of the quantity of Last Buy in the stage of EOL should fulfill the requirements such as fulfilling all products in the warranted period(Note5) at least, and proper quantity to prevent the production of dead materials and the cost increase of customer service department. Certainly, too much material preparation only influences the cost of customer service department, and too less material preparation could not fulfill the demands and induce the reduce of customer satisfactory degree and market proportion. So the confirmation of the quantity of Last Buy is the problem that enterprises must emphasize in this stage.

At present, we found many complex formulas about Last Buy quantity are very far from the actual demand quantity, so we summarized the following applied computation logic of Last Buy quantity as follows.

1. If the preparation materials are servicing materials, so the formula is

Components Qty= Sales quantity of finished product* PCFR* the proportion that the damaged ratio of the raw materials makes up the damaged ratio of the finished products- Stock- Total Usage

2. If the preparation materials are sales products, so the formula is

Buffer Qty= Sales quantity of finished product* PCFR* Dead Rate- Stock- Total Usage

Here, PCFR represents the accumulative damaged ratio of estimation (Note6), Dead Rate represent the proportion that 
the finished products which could not be repaired make up the finished products repaired back, Stock represents present stock, and Total Usage represents the quantity that the servicing materials or finished products have been used or consumed.

From the formulas, we can see that the sales data, Stock and Total Usage are easily obtained, and the Dead rate could be computed according the actual servicing situation (Note7).

PCFR is the accumulative product damaged ratio when the sale products pass the warranted period (Note8) in the future from the first month of sale to now. And because PCFR is the estimation, so the problem of accuracy exists and the computation of PCFR is one difficulty to compute (Note9) EOL safety stock for enterprises all along. In this article, we primarily studied PCFR, and hoped to offer some references for enterprises.

Suppose the average PCFR of all models up to OOW (Note10) is $4.5 \%$, and usually if certain future model is about to EOL, $4.5 \%$ will be the measured standard to compute PCFR, and every enterprise will possess its own computation method. In the computation method of this article, we take $4.5 \%$ as the experience value of PCFR, and we adjust the value of PCFR according to the proportion of actual servicing materials consumption and theoretical materials consumption to make the value of PCFR more approach the reasonable value.

Computation of CFR:

Suppose: $\mathrm{M}=$ actual consumption/ theoretical consumption

A. If $\mathrm{M} \geq 5$, so check up the accuracy of PCFR with relative technicians.

B. If $\mathrm{M} \in[3,5]$, so $\mathrm{PCFR}=3 * 4.5 \% * 0.6+4.5 \% * 0.4$.

C. If $\mathrm{M} \leq 3$, so $\mathrm{CFR}=(\mathrm{M}+1) * 4.5 \% / 2$.

Use above values of PCFR in the EOL buffer formula to compute.

Where, actual consumption= HQ consumption of customer service- the stocks of every maintenance point*1.2- OTW.

(Note: 1.2 is the stock of outsourcing maintenance point which could not be computed).

Theoretical consumption= present sales quantity* $4.5 \% *$ Dead Rate.

Modification: For EOL with substitute relationship, the higher order (Note11) could substitute the lower order (Note11) to make a group, and when the maximum order product (Note11) of the group is about to EOL, we make EOL for the whole group, and then compute according to above formula.

The study of PCFR in the article is only based on electric products, and for other products, there should be different computation methods.

\section{References}

Axsater S \& Zhang, Wenfa. (1999). A Joint Replenishment Policy for Multi-echelon Inventory Control. Int J Production Economics.

M. Ettl et al. (2000). A Supply Network Model with Base-stock Control and Service Requirements. Operations Research.

\section{Notes}

Note 1. TAT (Turn Around Time)

Note 2. customer service center

Note 3. warranty

Note 4. are all out of warranty

Note 5. in warranty

Note 6. is Predict Cumulated Failure Rate

Note 7. repair unit

Note 8 . are out of warranty

Note 9. calculate

Note 10. all OOW (Out Of Warranty) Model

Note 11. Model 